\title{
License to Cheat: Voluntary Regulation and Ethical Behavior
}

\section{Citation}

Gino, Francesca, Erin L. Krupka, and Roberto A. Weber. "License to Cheat: Voluntary Regulation and Ethical Behavior." Harvard Business School Working Paper, No. 13-029, September 2012.

\section{Permanent link}

http://nrs.harvard.edu/urn-3:HUL.InstRepos:9527321

\section{Terms of Use}

This article was downloaded from Harvard University's DASH repository, and is made available under the terms and conditions applicable to Open Access Policy Articles, as set forth at http:// nrs.harvard.edu/urn-3:HUL.InstRepos:dash.current.terms-of-use\#OAP

\section{Share Your Story}

The Harvard community has made this article openly available.

Please share how this access benefits you. Submit a story.

\section{Accessibility}


H A R VAR D

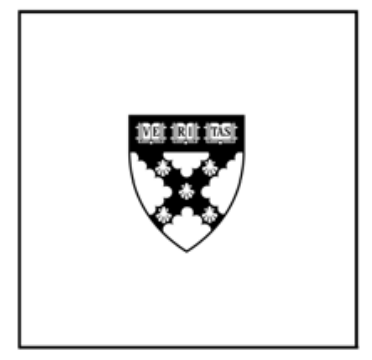

\section{License to Cheat: Voluntary Regulation and Ethical Behavior}

Francesca Gino

Erin L. Krupka

Roberto A. Weber

\section{Working Paper}

13-029

September 5, 2012 


\title{
License to Cheat: Voluntary Regulation and Ethical Behavior
}

\author{
Francesca Gino \\ Harvard University \\ Erin L. Krupka \\ University of Michigan \\ Roberto A. Weber \\ University of Zurich
}

September 5, 2012

\section{Acknowledgments}

The authors gratefully acknowledge the support of the staff and facilities of the Center for Behavioral Decision Research at Carnegie Mellon University and IZA Bonn for financial support. We also gratefully acknowledge the support of the Research Priority Program "Foundations of Human Social Behavior" at the University of Zurich. We thank Rachel Croson, seminar participants at the University of Michigan (Stiet seminar series) and the Berlin Behavioral Economics Seminar, and participants at the ESA, ASSA, and 2011 CESifo Behavioral Economics conferences for valuable comments. We thank Carolina Velez and Piper Lincoln for their help during data collection. 


\title{
License to Cheat: Voluntary Regulation and Unethical Behavior
}

\begin{abstract}
While monitoring and regulation can be used to combat socially costly unethical conduct, their intended targets are often able to avoid regulation or hide their behavior. This surrenders at least part of the effectiveness of regulatory policies to firms' and individuals' decisions to voluntarily submit to regulation. We study individuals' decisions to avoid monitoring or regulation and thus enhance their ability to engage in unethical conduct. We conduct a laboratory experiment in which participants engage in a competitive task and can decide between having the opportunity to misreport their performance or having their performance verified by an external monitor. To study the effect of social factors on the willingness to be subject to monitoring, we vary whether participants make this decision simultaneously with others or sequentially as well as whether the decision is private or public. Our results show that the opportunity to avoid being submitted to regulation produces more unethical conduct than situations in which regulation is either exogenously imposed or entirely absent.
\end{abstract}

Keywords: ethical behavior; dishonesty; regulation; selection; social norms

\section{Introduction}

The popular and business press regularly reports instances of unethical conduct by firms and individuals. Recent examples from the business world include fraudulent and deceptive banking, marketing, and securities trading practices, such as those involving Barclay's, Capital One, GlaxoSmithKline, and Bernard Madoff. These instances received considerable attention both for the seriousness of the ethical lapses involved and for their impact on economic and societal welfare. Tax fraud and avoidance by firms and individuals, believed to be commonplace, imply large revenue losses for governments and shift the fiscal burden elsewhere in society. In athletics, stunning individual achievements across many sports - e.g., cycling, baseball, and swimming - are often met with skepticism regarding the extent to which they resulted from the use of illicit performance-enhancing drugs. In academia, fraudulent research and student cheating pose serious challenges for the credibility of scientific inquiry and higher education.

Given the breadth of decision domains in which actors face decisions to be regulated and the farreaching consequences of such unethical behavior, it is important to examine how it can best be discouraged. One powerful tool on which policymakers can rely is regulation in the form of monitoring 
and sanctions. For example, the desire to limit predatory behavior and deceptive marketing practices on behalf of firms led to the creation of the Consumer Financial Protection Bureau, a product of the 2010 Dodd-Frank financial reform bill, which has the power to monitor firm practices and impose fines. Taxcollection agencies are given considerable power to investigate financial information and impose financial or criminal sanctions for underreported income. In athletics, regulatory entities, such as the World AntiDoping Agency, possess considerable power to test for banned substances and impose or recommend serious penalties. Indeed, prior research demonstrates that stronger monitoring and sanctions can discourage unethical conduct, though sometimes with limited effectiveness (e.g., Andreoni, et al., 1998; Nagin, et al., 2002; Olken, 2007).

One potential limitation of the effectiveness of regulation occurs when firms and individuals can influence the extent to which they are subject to rules and monitoring. For example, manufacturing firms confronted with varying state or national labor and environmental regulations may choose which set of regulations to follow by deciding where to locate (Levinson and Taylor, 2008; Hanna, 2010). Similarly, credit-card companies have historically incorporated in Delaware, which affords them the opportunity to avoid more stringent regulation elsewhere (see for example Ausubel, 1991). Firms also can give themselves the flexibility to behave unethically, as when deciding whether to voluntarily agree to be bound by a particular set of standards, such as the requirements of FairTrade or EPEAT green production. Along the same lines, Enron's well-known switch from historical cost (book value) to mark-to-market (fair value) valuation and its decision to suspend its code of ethics gave the firm added flexibility to engage in financial malfeasance.

Opportunities to influence the degree of regulation by which one is bound also exist at the individual level. An academic researcher may choose to submit research to journals with varying data availability and replication policies. A student may select universities or courses with varying oversight and policies to combat cheating. And a wealthy individual may choose to hide wealth from tax authorities by relying on bank accounts in countries with high degrees of banking secrecy. Similarly, during the 2012 U.S. presidential election, Republican candidate Mitt Romney chose not to publicly release more than a year's worth of tax returns, a decision that prevented public monitoring of his financial activities and potential conflicts of interest.

Even when they make no explicit choice among regulatory regimes, individuals and firms may have other avenues through which they can avoid monitoring and regulation. For example, anti-doping efforts in athletics are regularly hampered by medical advances that make detection difficult or impossible, thereby giving athletes or teams who engage in doping the ability to avoid regulation and monitoring altogether. Lobbying efforts and regulatory capture by firms can allow them to create loopholes or entirely avoid the enforcement of regulation. 
As these examples illustrate, regulation is often of limited effectiveness, not solely due to exogenous factors that make detection or enforcement difficult, but also because those who are supposed to be regulated may have the ability to determine how much regulation they face or even whether they face it at all. Thus, at least two types of choices may be critical in determining the degree to which unethical behavior occurs in contexts where it is possible. First, an individual or firm can choose to behave unethically, if given the opportunity. This kind of decision has been studied extensively, as we review below. Second, an individual or firm may be able to choose whether to have the opportunity to behave unethically, as in most of the cases discussed above. Despite the potential importance of these kinds of "voluntary regulation" choices, they have received relatively little research attention; similarly, the factors that influence "voluntary regulation" choices, and their ultimate consequences on unethical conduct, are not well researched.

In this paper, we explicitly study the decision of whether to voluntarily submit to stricter regulation and the extent to which this decision affects subsequent unethical behavior. Mirroring many of the situations described above, in which firms or individuals can obtain a financial or competitive advantage by behaving unethically, we study such behavior in a zero-sum competitive setting in which unethical conduct advantages one party at the expense of another. And, to obtain high levels of control over the presence and nature of regulation and the underlying behavior, we use a laboratory experiment in which we can carefully vary features of the environment while keeping all else constant.

Throughout the paper, we use the term "regulation" broadly, to refer to an effective form of monitoring and sanctions that prevents unethical conduct. For simplicity, we consider two extremes in terms of regulation: individuals' behavior is either entirely unregulated, such that they have the freedom to act as unethically as they would like, or entirely regulated, in which case they have no opportunity to behave unethically. We distinguish between exogenous regulation, which is imposed on individuals by an outside entity (i.e., the experimenter) without opportunities for avoidance, and endogenous voluntary regulation, under which the same regulatory regime is present but each individual can decide whether his or her own behavior is subject to regulation.

We focus on two major decisions that participants in our experiment make. First, we study their choice of regulation (when regulation is voluntary) and the factors that affect their willingness to be subject to regulation. Second, we study the ultimate unethical behavior following this initial choice - i.e., the extent to which they over-report their performance in order to obtain greater financial gains.

In the experiment, participants perform a simple task and receive a payoff based on whether their resulting score is higher than that of another participant (cf. Gino, Ayal, and Ariely, 2009). In two baseline conditions, participants cannot choose whether an experimenter verifies the accuracy of their performance: in a mandatory-regulation condition, the performance of all participants is verified; in a no- 
regulation condition, all participants are free to report any score, and none of the reported scores are verified. We compare the scores obtained in these two conditions with voluntary-regulation conditions in which we allow participants to choose, before they engage in the task, whether to have their scores verified. Thus, we observe participants' decisions of whether to be regulated as well as the resulting score they obtain.

To understand how psychological and social factors may influence regulation choice in the voluntary-regulation conditions, we also introduce treatments that vary two factors: (1) whether the decision is made privately (where a subject's choice to be regulated is not observed by other participants) or publicly (where regulation choices are observed by the other participants), and (2) whether the decision is made simultaneously or sequentially. These treatments also allow us to examine how information about others' regulation choices influences individuals' decisions regarding whether to be regulated, as well as their resulting scores in the competitive task.

Our results show that there is significantly more misreporting under voluntary regulation (where participants have a choice of whether to be regulated) than when they are either all submitted to mandatory regulation or when no opportunity for regulation exists. This is despite the fact that a significant proportion of participants opt to be regulated in the voluntary treatments. Thus, allowing individuals to voluntarily choose whether to be subject to regulation might lead to greater unethical behavior than when behavior is completely unregulated. We find that selection based on relative skill plays a role in determining who opts for regulation (such that those likely to perform worse on the competitive task opt to not be regulated) and that the choice to not be regulated appears to give participants greater license to cheat, relative to when regulation is entirely absent.

We also examine whether the presence or absence of regulation in one context influences behavior in other domains. Keizer et al. (2008) find that disorderly and petty criminal behavior in one setting has a spillover effect that triggers more disorderly and petty criminal behavior in a second setting. Similar spillover effects may occur in the case of ethical behavior. To explore such potential "ethical spillovers," we use a second non-skill based competitive task in which no regulation exists and participants can therefore report any score they wish. We find that misreporting of scores in this second task is affected by the presence or absence of regulation in the first task; specifically, our results show that any possibility of misreporting scores in the first task yields greater unethical conduct in the second task. That is, in terms of ethical spillovers to other contexts, having regulation that is avoidable (voluntary) yields similar outcomes as when regulation is entirely absent, and both conditions are worse than mandatory and inescapable regulation.

In addition to contributing to the understudied behavior of regulation decisions, our findings have important practical implications. Unethical conduct itself is often difficult to observe or verify, but, in 
many situations, the initial choice regarding whether to have the flexibility to behave unethically is much easier to observe. Our results suggest that policies that impose either no regulation or total regulation may be preferable to policies that allow for regulation that can be easily circumvented. ${ }^{1}$ We also find that increasing the visibility of the choice to be regulated can be used as a tool to enhance the voluntary adoption of regulation and decrease subsequent unethical behavior. Finally, we show that a policymaker's choices concerning the presence of regulation in one domain can affect behavior in other, unregulated contexts.

The rest of the paper is structured as follows. In section 2, we review the relevant literature and develop hypotheses that we test in our experiment. In section 3, we describe the experimental design. In section 4, we present our results. We discuss the main findings and conclude in section 5.

\section{Relevant Literature and Hypotheses}

Partly because of its pervasiveness in organizations and society more broadly, unethical behavior has attracted the attention of scholars from various disciplines. Much of the research examines the causes and consequences of unethical behavior in economic, organizational, and political contexts (Gneezy 2005; Fisman and Gatti 2002; Gino, Ayal, and Ariely, 2009; Burks and Krupka 2012).

Using evidence from both field and laboratory studies, this research generally explores the extent to which people behave unethically and the factors that influence the degree of unethical behavior when people have the opportunity to lie or cheat. For example, Carpenter, Matthew, and Schirm (2010) found that sabotage among coworkers is higher in tournaments than it is under piece-rate compensation. Pierce and Snyder (2008) showed that unethical conduct by automobile inspectors is influenced by the presence of unethical conduct in the organization where those inspectors work. Related research conducted in laboratory settings examines how individuals' unethical behavior often arises through vertical specialization, which diffuses the responsibility for behaving unethically (Ellman and Pezanis-Christou, 2010; Hamman, Weber, and Loewenstein, 2010). A growing body of research also notes the ways in which people are self-serving in their interpretation of what constitutes ethical behavior (for reviews, see Ayal and Gino, 2011; Dana, Loewenstein, and Weber, 2011). Finally, a substantial literature examines the effects of ethical norms or behavior among management and employees in firms, often relying on survey or field data (Jones and Kavanagh, 1996; Schminke et al., 2005; Trevino et al., 2008).

One focus of research on unethical behavior has been to explore the conditions under which individuals behave dishonestly for (monetary) personal gain. For instance, Gneezy (2005) studied the extent to which a laboratory participant with private information will lie to an uninformed participant

\footnotetext{
${ }^{1}$ One application of this is the concern over "carbon leakage," or "...the fear that industrial activity and greenhousegas emissions will 'leak' from economies with tough environmental rules to unregulated economies. A big point of concern in the U.S. climate debate, prompting many senators to call for tariffs on imports from countries without similar environmental legislation." (Wall Street Journal Europe, 13 March 2008).
} 
about which of two possible actions is more profitable. He found that people are sensitive to both their potential gains from a lie and to their counterparts' potential losses (see also Croson 2005; Hurkens and Kartik, 2009; Sutter, 2009; Gibson, et al., forthcoming; Erat and Gneezy, forthcoming). Recent research also explores the conditions under which individuals lie about the outcome of a random process, such as a die roll, to gain more money from an experimenter (Gino and Ariely, 2012; Shalvi, et al., 2011; Fiscbacher and Heusi, 2008). Other recent work examines how misreporting a score on an individual piece-rate task is affected by social and organizational factors. For example, Gino and colleagues found that exposure to other people's unethical behavior increases an individual's dishonesty when the wrongdoer is an in-group member (Gino et al., 2009) or when the individual feels similar to the wrongdoer (Gino \& Galinsky, 2012). ${ }^{2}$

Similar to the above research, our study explores unethical behavior in situations where lying can yield better financial outcomes. Our specific focus is on the effectiveness of regulation and monitoring, particularly when these can be easily circumvented. That is, we study what happens when individuals have the opportunity to decide whether to voluntarily subject themselves to regulation that prevents misreporting. The predicted consequences of such voluntary regulation are unclear. Since our work is exploratory, we develop plausible hypotheses as a way of understanding alternative results that we might obtain.

To generate our first hypothesis, we begin by noting that individuals who are given the choice to opt for "no regulation" have the same opportunity to behave unethically as those who are in a context where there is no possibility of regulation. This holds in our voluntary-regulation conditions, where any participant who wishes to misreport her score can forego regulation and do so. Therefore, if there are some individuals who are always willing to lie for money and others who are not, it follows that unethical behavior in a treatment where individuals are free to privately choose whether to be regulated will not differ from unethical behavior when the behavior of all individuals is unregulated. ${ }^{3}$ Under voluntary regulation, those individuals who prefer to behave unethically will choose to be unregulated when offered the choice, and individuals who prefer to behave ethically will do so regardless of whether they are regulated. This yields our null hypothesis:

\section{$H_{0}$ (null): Under voluntary regulation, misreporting will be similar to that under no regulation.}

\footnotetext{
${ }^{2}$ Burks and Krupka (2012) find that alignment between one's own views regarding ethical practices and those of one's peers (in-group members) is correlated with ethical behavior.

${ }^{3}$ An implicit assumption is that regulation choices themselves are not subject to social pressure or consequences, which is true when they are made privately (as when a taxpayer secretly opens a bank account in a tax haven or an athlete privately obtains the ability to circumvent testing). In cases where the regulation choice is made publicly - as when a firm chooses to locate in a country with lax labor regulations or when a researcher opts to publish in journals with lax data-availability policies - social costs associated with the regulation choice may influence behavior. We address this possibility below and in our experiment.
} 
The above null hypothesis simply states that voluntary regulation affords equal opportunity for unethical behavior as does the absence of regulation; this hypothesis serves as a benchmark against which to compare what actually happens when regulation is present but avoidable. However, if voluntary regulation leads to different outcomes than the mere absence of regulation, why might that be? We explore possible explanations for how the act of choosing regulation might give rise to different subsequent behaviors regarding cheating.

The decision of whether to avoid regulation may be more readily observable to outsiders than cheating itself. For example, a student's decision to cheat on an exam, when given the opportunity to do so, is typically unobservable. But the decision to select a university or courses with more lax misconduct enforcement is potentially observable by others and therefore more likely to be subject to social pressures. Similarly, a private firm that closes its books to external parties gains considerable flexibility for its behavior, but the decision to close the books can be publicly observed. Prior research finds that being observed by another person affects ethical conduct (Akerlof and Kranton, 2010; Jones and Kavanagh, 1996; Gino et al., 2009; Gino, Gu, and Zhong, 2009; Goldstein et al., 2011; Ariely et al. 2009), as well as behavior in other contexts outside of ethical decision making, as shown both in psychology (e.g., Asch, 1956; Kallgren et al., 2000; Haley and Fessler, 2005; Bateson et al., 2006; Burnham and Hare, 2007) and in economics (Charness et al., 2007; Rigdon et al., 2009).

In our context, when the decision to be regulated is publicly observable, we predict this will increase the number of individuals opting to be regulated because of social pressure to opt for regulation. If fewer people choose to circumvent regulation (through a choice made publicly), the result is likely reduced unethical behavior relative to conditions where voluntary regulation choices are private.

$H_{1}$ (social pressure): If voluntary regulation choices are made publicly, more individuals will opt to be regulated, and this increased regulation will result in less misreporting.

Thus, for example, while U.S. presidential candidates are not required to publicly release tax returns, the fact that their decision to do so is public has generally led to greater openness to public monitoring and presumably less unethical behavior in tax reporting.

In a similar vein, considerable research demonstrates that people are influenced by what they observe others doing (Deutsch and Gerard, 1955; Zey-Ferrell et al., 1979; Zey-Ferrell and Ferrell, 1982; Jones and Kavanagh, 1996; Brass et al., 1998; Schultz et al., 2007; Krupka and Weber, 2009; Bicchieri and Xiao, 2009; Gino \& Galinsky, 2012). A person's decision to be regulated may also be influenced by observing the frequency with which others opt for regulation. Drawing on the distinctions Deutsch and Gerard outline in their seminal 1955 paper on social influences, we describe this kind of influence as a social information influence, whereby people learn something about the frequency with which an action 
is taken from observing others. When others take a particular action, an individual becomes more likely to make the same choice. Therefore, we predict that individuals' voluntary-regulation choices will be influenced by the publicly observable regulation choices of earlier movers. Observing another person choose regulation will increase a participant's likelihood of choosing regulation and reduce unethical behavior relative to when earlier movers choose to be unregulated.

$\mathrm{H}_{2}$ (social information): If voluntary-regulation choices are public and sequential, then individuals' regulation choices will be influenced by early movers. These regulation choices will also determine the amount of misreporting.

The above two hypotheses focus on social influences, whereby information - either about one's own choice that is provided to others or about others' choices that one receives prior to opting for or against regulation - affects the voluntary-regulation choice and subsequent unethical behavior. But the voluntary regulation decision may also interact with the subsequent decision to behave unethically in a manner that is not influenced by public information about behavior.

For example, an individual's initial decision regarding whether to abide by regulation might take place in a "cooler" emotional state, when the person does not feel the temptation or competitive pressure to behave unethically, or when this feeling of temptation is psychologically more "distant" and thus also less salient (Trope and Lieberman, 2010; Tenbrunsel, et al., 2011). In fact, as demonstrated by Mead et al. (2009), cheating is more likely to occur when people are in a "hot" state -- that is, when they are cognitively depleted or have little self-control. As a result, the individual may opt to be subject to regulation under the mistaken belief that she will behave ethically even without it. This means that some people, who would ultimately behave unethically if the temptation to cheat were psychologically "closer," may initially opt to be regulated and thereby constrain their subsequent conduct. Consistent with this argument, psychological research has robustly demonstrated that individuals poorly anticipate what subsequent choices they will make (Diekmann et al., 2003; Woodzicka and LaFrance, 2001). Thus, committing in advance not to cheat, when it is easier to do so, may lead to less unethical conduct. ${ }^{4}$

Alternatively, it is also possible that the initial private decision of whether to be regulated would offer a psychological path to increased, rather than reduced, unethical behavior. If people view the initial voluntary-regulation decision as one with only minor ethical implications - since, after all, they can always report truthfully later - then they might find it easy to forgo regulation. However, having gone down the path of foregoing regulation, people may then find it psychologically easier to behave unethically. That is, people may view their initial decision regarding regulation as not very ethically

\footnotetext{
${ }^{4}$ Consistent with this prediction, Sherman (1980) found that study participants over-predicted their own tendency to behave in a socially desirable manner (e.g., refusing to write an essay that advocated an opinion counter to their own), but these over-predictions were "self-erasing" in that participants subsequently tended to behave consistently with their own predictions.
} 
important ("I'm not doing anything wrong by giving myself an option to cheat"), but may then subsequently rely on that decision as a way to guide their subsequent ethical choices ("Since I gave myself the option, I may as well use it"). In a similar way, psychological research has shown that an initial small act showing commitment to a course of action can facilitate subsequent larger acts (Freedman and Fraser, 1966).

The two possibilities we discussed above suggest how voluntary regulation may affect subsequent unethical behavior even when an individual is unconcerned about others' behavior or what others think of her own behavior. We test these possibilities in our "private" conditions, where participants do not observe others' regulation choices. Since the above discussion yields two different directional predictions, our hypothesis posits an effect but leaves open the direction.

$\mathrm{H}_{3}$ (behavior facilitation): Private voluntary regulation will either increase or decrease unethical conduct relative to when regulation is absent.

We now turn to describing the experimental design we use to test our hypotheses.

\section{Experimental Design}

Our experiment compares two conditions, one in which there is no regulation and one in which everyone is regulated (mandatory regulation), to conditions in which individuals can choose to avoid being regulated (voluntary regulation). To explore the influence of timing and social pressure on individuals' regulation decisions, we conduct four variants of voluntary regulation. Specifically, we vary whether participants make regulation choices privately vs. publicly and simultaneously vs. sequentially. That is, the voluntary-regulation conditions use a 2 (private vs. public choice) X 2 (sequential vs. simultaneous choice) design. Therefore, the experiment employed six conditions in total, summarized in Table 1.

Participants were recruited to the laboratory in groups of six. In all conditions, they completed a problem-solving task and self-scored their performance. In the no-regulation condition, participants selfreported their scores on the problem-solving task, and the experimenter did not verify these scores. In the mandatory-regulation condition, participants reported their scores, and the experimenter verified their performance (as described in detail below).

\section{Insert Table 1 about here}

In four voluntary-regulation conditions, participants chose whether their self-reported score would be verified or not by the experimenter. All choices regarding whether to be regulated in the voluntary-regulation conditions were made prior to the competitive problem-solving task but after the experimenter explained this task in detail. An important aspect of our study design is that, in the case of 
voluntary regulation, all participants had the opportunity to behave unethically. That is, any participants who selected not to be regulated had the same opportunity for unethical behavior as did participants in the conditions where there was (exogenously) no regulation.

We recruited voluntary participants for a paid one-hour experiment from the participants' pool of the Center for Behavioral Decision Research at Carnegie Mellon University. On average, participants received $\$ 14.56$ as payment for their participation. A total of 276 individuals participated in 46 sessions consisting of six participants each.

Upon arriving at the laboratory, participants were seated at one of six tables, which were distant enough from one another so that participants could not see each other's choices during the study. Tables were numbered from 1 to 6 . The study included two competitive constant-sum tasks, a risk task and a questionnaire. These tasks were completed one after another, and payments were not revealed until all tasks were completed.

\subsection{Task 1: Matrix Task}

As their first task, and the main task in our study, participants completed a competitive problemsolving task, which has been used to measure unethical behavior in prior work (Mazar et al., 2008; Gino et al., 2009). Each participant received two sheets of paper: the first was a worksheet with 20 matrices, each containing a set of 12 three-digit numbers (e.g., 5.78). In this task, participants had four minutes to find two numbers in each matrix that summed to 10. Participants then reported how many matrices they solved. The time constraint is generally insufficient for participants to solve all 20 matrices. Our primary interest is in the extent of misreporting in this task.

The second sheet was a collection slip on which participants reported their performance. After the four minutes had passed, participants folded their worksheet and placed it on their desk and then wrote down their performance score (i.e., the number of matrices they correctly solved) on their collection slip.

Participants were paid for this task based on their own score and the score of one other, anonymous, participant. The experimenter randomly selected this participant from among the other participants in the same session. The experimenter compared pairs' scores privately, so participants did not learn the identity of the other participant with whom they were paired. If the score of one participant in the randomly chosen pair was higher than the other person's score, then the high scorer received $\$ 6$, and the low scorer received $\$ 3$. In the case of a tie, the experimenter flipped a coin to determine who in the pair received $\$ 6$ and who received $\$ 3$.

We used this procedure so that cheating on the matrix task by over-reporting performance would be costly to another participant in the same session. This assures that the costs of cheating are salient, well understood, and meaningful to participants who are deciding whether to cheat. By contrast, in much related prior work (e.g., Fischbacher and Heusi, 2008; Gino et al., 2009), the costs of cheating were often 
unclear, as participants would simply receive a higher payment from the experimenter when they lied about their performance on a problem-solving task, thus making unclear who would be impacted by their cheating, for are at least two reasons. First, the additional money that participants obtained was not clearly taken from an identifiable other; the money presumably was not the researcher's own money, and it is not clear how else the money might be used if not to compensate the participant. Second, participants might have interpreted the research context as one in which the researcher wanted some participants to misreport, thus providing the plausible impression that the researcher's purpose might have benefitted from misreporting. Therefore, we believe that our design, in which misreporting clearly creates an unfair advantage relative to another participant, represents an improvement in making misreporting more likely to be interpreted as unethical.

In the mandatory-regulation condition, the experimenter verified participants' score on the matrix task. The instructions informed participants that, later in the experiment, they would hand both the collection slip and the worksheet to the experimenter and that the experimenter would verify that the score was correct (and correct it if it was not) before determining the payment for each pair of participants. In the no-regulation condition, instead, there was no such verification of performance by the experimenter. In this condition, the instructions informed participants that, later in the experiment, they would only hand the collection slip to the experimenter and that the experimenter would use only the score on this slip to determine payment. Participants in the no-regulation condition could take their worksheet with them at the end of the experiment.

In the voluntary regulation conditions, participants could choose whether or not they wanted the experimenter to verify their score. Participants were told,

"You may choose one of two options for reporting your score:

1. Green Reporting Option: You will report your own score at the end of the experiment and the experimenter will verify that your score is correct. You will hand in both your sheet with the 20 matrices and your Score Reporting Slip to the experimenter. The experimenter will verify the number of matrices that you have correctly solved. Your verified score will be compared to another participant's score to determine your payment.

2. Blue Reporting Option: You will report your own score at the end of the experiment but the experimenter will not verify that your score is correct. You will only hand in your Score Reporting Slip to the experimenter but you will not hand in the sheet with the 20 matrices. You are free to take it home with you. Your self-reported score will be compared to another participant's score to determine your payment."

The way in which participants selected between the above reporting options varied across conditions. In particular, we manipulated choice visibility (public vs. private) and choice timing (simultaneous vs. sequential), leading to the following four voluntary-regulation conditions: 
- Private-simultaneous: Participants selected the reporting option by privately choosing one of two boxes on their instruction sheet. Participants were instructed to do so at the same time. Following these choices, the experimenter went around the room and privately recorded each individual's reporting option.

- $\quad$ Private-sequential: Participants again made their reporting decisions privately by selecting a box on their instruction sheet. In this treatment, however, the experimenter, instructed participants to do so by turn (by having participants wait until the person ahead of them had recorded their choice). After all participants had selected a reporting option, the experimenter went around the room and privately recorded their choices.

- Public-simultaneous: Participants all made their reporting decisions at the same time but were able to observe the reporting choices made by all other participants in their session after doing so. Prior to the session, we placed a blue and a green index card on each participant's desk so that they could use them to indicate their choices in the public conditions by raising one of the two cards. When it was time to select a reporting option, participants privately chose one of the two cards, and then, publicly, each person simultaneously raised either the blue or green card so that everyone could see the frequency of each choice.

- Public-sequential: Participants also indicated a reporting option by raising a card publicly. But, rather than making choices simultaneously, they proceeded one at a time, prompted by the experimenter, so that all participants could see the choices of others before them in the session.

We note that, given our design and procedure, we were able to record participants' true task performance only for those in the mandatory-regulation condition and for regulated participants in the voluntary-regulation conditions. We were not able to directly observe true task performance for unregulated participants in the voluntary-regulation conditions, since these participants had the opportunity to lie about their performance without leaving evidence of their actions. In fact, they could take home their worksheet with their real answers at the end of the study.

\subsection{Task 2: Die Roll}

Upon completion of the first task, but before the experimenter determined the results of this task, participants completed a second competitive task in which all participants, regardless of what condition of the matrix task they were previously in, had the opportunity to misreport their score. We included this task to measure how the experience from the different treatments in the first task may spill over and affect unethical behavior in a second task, in which everyone has the opportunity to behave unethically due to the absence of regulation.

Each subject received a die in a plastic cup. The experimenter asked participants to roll the die by placing their hand over the cup and shaking it. Next, participants privately wrote down the number 
produced by the die roll. This number determined their score for this task. After recording their score, participants were asked to shake the cup again to change the position of the die. Thus, participants had the opportunity to misreport the outcome of the die roll. ${ }^{5}$

In the die-roll task, each participant was again randomly and anonymously matched with another participant in the room. It was made clear that this was a different participant than the one with whom the participant had been matched in the first task. Participants' payment in this task again depended on their score and the other person's score. As before, if the participant's score was greater than the other person's score, then the participant received $\$ 6$. If it was lower, then the participant received $\$ 3$. In the case of a tie, the experimenter flipped a coin to determine who in the pair received $\$ 6$ and who received $\$ 3$.

\subsection{Risk Task and Final Questionnaire}

As their third task, participants made choices that we used to assess their risk preferences, as a possible control for individual differences. Any payment they accumulated from this task was added to their other payoffs from the other parts of the experiment. We assessed individual risk preferences using Binswanger's (1980) procedure. Participants were presented with eight options specified in different rows of a table printed for them on a piece of paper. Each option provided them with a payoff if the outcome of a coin flip was "Heads" and another payoff if it was "Tails." Participants were asked to choose one of these options. The experimenter then went around the room and tossed a coin to decide which payment each participant received based on their decision. The row chosen by a participant provides an estimate of his or her risk preferences.

As their last task in the study, participants then answered a questionnaire asking about their gender, age, occupational status, and personality. While they worked on the questionnaire, one of the two experimenters left the room to calculate participants' payoffs. To compute payoffs, this experimenter used the collection slips from task 1 and task 2, together with the matrix sheet if the participant was to be regulated. Next, after participants completed the questionnaire, they each left the room one at a time to receive payment privately.

\section{Results}

Table 2 presents a summary of the main outcome variables from the matrix task across conditions, namely participants' reported matrix scores and their voluntary regulation choices. Recall that in the no-regulation condition, the mean matrix score is a self-reported score that the experimenter did not verify; in the mandatory-regulation condition, the mean matrix score is the verified score; and in the voluntary-regulation condition, the mean matrix score includes both verified and unverified scores. Under

\footnotetext{
${ }^{5}$ Our design is similar to the one employed by Fischbacher and Heusi (2008), in which participants privately roll a die and receive as payment what they report the die roll to be. Similar procedures in which participants can misreport the outcome of a random process like a die roll or a coin toss for personal gain have also been used in previous psychological research (e.g., Bateson, et al., 1999; Shalvi, et al., 2011; Gino and Ariely, 2012).
} 
mandatory regulation, participants correctly completed, on average, 5.40 matrices (out of 20). However, when the experimenter did not verify the scores (no regulation), participants reported completing 9.07 matrices on average. These means differ significantly in a t-test $\left(\mathrm{t}_{58}=3.65, \mathrm{p}<0.001\right)$, and the distributions of scores differ significantly in a non-parametric Wilcoxon rank-sum test $(\mathrm{z}=3.49, \mathrm{p}<$ 0.001). Therefore, giving everyone the opportunity to misreport resulted in higher reported scores. This result is consistent with prior research showing that when given the opportunity to cheat, people do cheat, even if only by a little bit and not to the maximum extent possible (Mazar et al., 2008; Gino et al., 2009).

\section{Insert Table 2 about here}

The remaining five rows of Table 2 report outcomes from the voluntary-regulation conditions, where participants could each choose whether or not they wanted to be regulated. We first pool all conditions with voluntary regulation and then report the results separately for each of the sub-treatments.

\subsection{Does voluntary regulation look like no regulation?}

Our null hypothesis predicted that, in the voluntary-regulation environment, scores on the matrix task would be similar to those when there is no regulation. This hypothesis is rejected in the data. The mean reported score pooled over all the voluntary-regulation conditions was 12.20 (row 3 in table 2), which is significantly higher than under no regulation $\left(\mathrm{t}_{244}=2.94, \mathrm{p}<0.005\right)$. Again, the distributions also differ significantly $(z=2.74, p<0.01)$. Thus, on aggregate, when participants can decide whether or not to be regulated, we observe more misreporting than when everyone is unregulated and has the opportunity to misreport. This is perhaps most surprising when one considers that $42 \%$ of the participants in the voluntary-regulation conditions opted for regulation.

When we compare the separate sub-treatments with voluntary regulation to the no-regulation condition, we similarly observed higher reported scores in all of the four conditions in which participants could avoid regulation. In three of these cases, the mean reported scores are significantly higher than under no regulation (private-simultaneous: $\mathrm{t}_{82}=3.88, \mathrm{p}<0.001$; private-sequential: $\mathrm{t}_{82}=3.99, \mathrm{p}<0.001$; public-sequential: $\left.t_{82}=2.10, p<0.04\right)$, while in the public-simultaneous case, the mean reported scores are also higher, but the difference is not statistically significant $\left(t_{82}=1.05\right)$.

\subsection{Do public regulation choices lead to greater regulation?}

We hypothesized that more participants would opt to be regulated when voluntary-regulation choices are public rather than private and that this would result in less unethical conduct $\left(\mathrm{H}_{1}\right)$. When participants make voluntary-regulation decisions publicly, they are indeed more likely to opt to be regulated (on average, $52.7 \%$ of the time) than when they make these decisions privately (on average, $31.5 \%)$, with the two frequencies differing significantly $\left(\chi^{2}(1)=10.04, p<0.005\right)$. Therefore, even though the decision to avoid regulation does not necessarily imply unethical conduct, participants appear 
concerned with the social image produced by having others know that they are forgoing opportunities to cheat. Turning to the reported scores, mean reported scores are lower when voluntary-regulation decisions are public than when they are private. In the two public conditions, the mean score is 10.82 , which is lower than in the two private conditions (13.57). This difference in means is statistically significant $\left(\mathrm{t}_{214}=\right.$ $3.67, \mathrm{p}<0.001)$, as is the difference in distributions of scores $(\mathrm{z}=3.57, \mathrm{p}<0.001)$. Therefore, consistent with $\mathrm{H}_{1}$, we observe that public voluntary-regulation decisions yield both greater regulation and less misreporting than when decisions are made privately.

In addition to increasing the percentage of participants who choose to be regulated, the public condition also yields lower reported scores among those who choose to be unregulated. In Figure 1, we present reported scores in the voluntary-regulation conditions by whether a subject chose to be regulated or unregulated and by whether the regulation decision was made privately or publicly. For those participants who opted for no regulation, mean reported scores are significantly higher for those in private conditions than for those in public conditions $\left(16.13\right.$ vs. $\left.13.21, \mathrm{t}_{123}=3.35, \mathrm{p}<0.005\right)$. In contrast, there is no significant difference in mean reported scores for those participants opting for regulation in the private vs. public conditions $\left(8.00\right.$ vs. $\left.8.68, \mathrm{t}_{89}=0.75\right)$. This indicates that the decline in misreporting that we observe in the public conditions, relative to when regulation choices are private, is driven both by an increase in the percent of participants choosing to be regulated and by a decrease in misreporting even among those participants who are unregulated. This is also our first piece of evidence that the effects of voluntary regulation may go beyond simply affecting the frequency of misreporting, but may also affect the magnitude of misreporting by those who are unregulated.

\section{Insert Figure 1 about here}

\subsection{Are participants influenced by others' regulation choices?}

We also hypothesized that, in the public-sequential condition, participants' regulation choices and misreporting would be influenced by others' earlier choices $\left(\mathrm{H}_{2}\right)$. Comparing the frequency with which regulation was chosen in the public-sequential and public-simultaneous conditions in Table 2 reveals no statistically significant differences in the frequency with which participants opt for regulation $(51.9 \%$ vs. $\left.53.7 \%, \chi^{2}(1)=0.037\right)$ or the resulting mean reported scores $\left(11.39\right.$ vs. $\left.10.26, \mathrm{t}_{106}=1.08\right)$. Therefore, there appears to be no change in aggregate behavior when public decisions are made simultaneously or sequentially.

However, an influence of sequential decisions emerges when we explore the behavior of participants across positions in the experiment. Recall that the subject with ID\#1 acted first, ID\#2 second, and so forth. Therefore, we can consider the behavior of participants in a session by ID number as a way of discerning the hypothesized dynamic effects in the sequential-public treatment. Table 3 presents the 
voluntary-regulation choices by subject ID (position) for all sessions in this treatment. We order the sessions by the regulation choice of the participant who moved first in each session.

\section{Insert Table $\mathbf{3}$ about here}

Table 3 reveals a considerable influence of earlier movers on subsequent regulation choices, consistent with our hypothesis. Given the overall frequency of $51.9 \%$ with which participants chose regulation in these treatments, we would expect two participants, selected at random and deciding independently, to make the same choice $50.1 \%$ of the time. Yet we find that in $77.8 \%$ of choices, a participant repeated the choice made by the previous participant, which differs significantly from the above expected proportion under independence $(\mathrm{z}=3.71, \mathrm{p}<0.001)$. In fact, the influence of early movers is so strong that, in the four groups in which the first mover chose regulation (the gray columns in Table 3), $80 \%$ of the subsequent participant choices were for regulation. On the other hand, in the five groups in which the first mover opted not to be regulated (the white columns in table 3 ), only $32 \%$ of subsequent participants opted for regulation.

The difference in the adoption of regulation by early movers also affects the scores subsequently reported in each session. In the four sessions in which the first mover opted to be regulated, the mean reported score was 9.7 (10.4 if we omit the first mover), while in the five groups in which the first mover chose no regulation it was 12.8 (12.0 if we omit the first mover). However, the difference, when we omit the first mover, is not statistically significant.

\subsection{Does private voluntary regulation affect unethical conduct?}

The results presented above demonstrate that public voluntary-regulation decisions can affect unethical behavior, both through individuals' concern about others knowing whether or not they opted for regulation and through individuals following the regulation choices made by earlier movers. We next study how unethical conduct is influenced by the possibility of forgoing regulation, even when voluntary regulation choices are made privately. In such cases, the social influences of being observed and of observing others discussed above are unlikely to play a role. Since all participants can give themselves the option to misreport, one might expect outcomes to be very similar to the no-regulation condition, making the private voluntary-regulation conditions the most likely to support our null hypothesis of no effect of voluntary regulation relative to no regulation. However, as we hypothesized earlier $\left(\mathrm{H}_{3}\right)$, the act of first deciding whether one wants to have the opportunity to behave unethically may be psychologically distinct from simply having the opportunity to misreport.

From Table 2, we see that across both conditions with private voluntary regulation, $31.5 \%$ of participants opt to be regulated. This could either represent only those participants who would not misreport under no regulation (as in our null hypothesis) or some participants who would misreport under 
no regulation but decide to constrain themselves under voluntary regulation. In either case, however, we might expect the resulting scores to be bounded above by those under no regulation (9.07). Instead, the mean score reported in the private conditions is 13.57 (private-simultaneous: 13.48, private-sequential: 13.67), which is significantly higher $\left(\mathrm{t}_{136}=4.17, \mathrm{p}<0.001\right)$. The distributions also differ between no regulation and private voluntary regulation $(\mathrm{z}=3.99, \mathrm{p}<0.001)$. Therefore, we again find evidence contrary to the null hypothesis that voluntary regulation will yield similar outcomes to no regulation: in our data, allowing participants to choose to be regulated yields significantly higher misreporting, even though roughly one-third of participants choose to be regulated.

\subsection{Why is there greater unethical behavior under voluntary regulation?}

The preceding result is somewhat surprising: If one-third of participants opt for regulation when doing so is a private decision, then why are mean reported scores higher than when no one is regulated? This suggests that, among those choosing to remain unregulated under voluntary regulation, misreporting is significantly higher. In this section, we attempt to shed light on what may be driving this result.

\section{Insert Table 4 about here}

Table 4 presents the mean reported score, by condition, broken down by whether a subject was regulated or unregulated. In the two baseline conditions (no regulation, mandatory regulation), participants were either all regulated or unregulated, while in the voluntary-regulation conditions, each participant chose this for themselves. Interestingly, the mean reported scores are higher for participants under voluntary regulation, both in a comparison between those who chose not to be regulated and those who were in the mandatory no-regulation condition $\left(14.94\right.$ vs. $\left.9.07, \mathrm{t}_{153}=6.05, \mathrm{p}<0.001\right)$ and in a similar comparison between those who chose regulation and those subject to mandatory regulation (8.43 vs. 5.40, $\left.\mathrm{t}_{119}=3.46, \mathrm{p}<0.001\right)$.

This pattern of scores may have at least two explanations. First, regarding the change in scores of those who were regulated, whether voluntarily or mandatorily, those participants who opt for regulation when doing so is voluntary may tend to have higher-than-average ability on the task. Low-ability participants opt out of regulation at higher rates, which explains the increase in scores, from 5.40 to 8.43 , among those who are regulated voluntarily. In short, a different group of participants is being regulated in the voluntary-regulation condition than in the mandatory-regulation condition. ${ }^{6}$ Below, we explore the evidence for such selection based on differences in individuals' ability.

\footnotetext{
${ }^{6}$ Dohmen and Falk (2011) nicely demonstrate the impact of sorting, by productivity, in the context of varying output contracts. See also Schwieren and Weichselbaumer (2010), who find a tendency for low-ability types to cheat more in competitive tasks.
} 
The above phenomenon alone does not explain why average scores also increase for voluntarily unregulated participants. A second phenomenon appears to be that those participants choosing to be unregulated subsequently misreport to a higher degree than they would if they were forced to be unregulated. This pattern is consistent with a "license to cheat effect," whereby choosing not to be regulated leads to greater misreporting than when no such choice is offered in the first place. We now turn to offering evidence for both of these effects.

\subsubsection{Selection effect}

To identify selection effects in determining whether participants opt for regulation, we first identify whether any observable participant characteristics predict the decision to be regulated. Table 5 reports the marginal effects from two probit regressions of the decision to be regulated, in the voluntaryregulation conditions, on demographic characteristics obtained at the end of the experiment, as well as on a binary variable indicating whether the regulation decision was public.

\section{Insert Table 5 about here}

The four demographic variables in the first model are i) whether a participant is female, ii) a participant's age, iii) whether a participant reports having at least one parent who graduated from college, and iv) whether a participant reports being religious. We also include, as a control, a variable for whether the regulation decision was made publicly (vs. privately). The second regression model also introduces binary variables to identify the most frequent college majors reported in our sample. Confirming our earlier analysis, if a participant's regulation decision is public, then that participant is 24 percent more likely to opt for regulation. The only other variable that significantly predicts regulation is gender; females are roughly 18 percent less likely to opt for regulation than males. This suggests that some of the potential selection observed in Table 4 might be accounted for by the differential regulation behavior of females.

To explore whether selective adoption of regulation by gender might be at least partly responsible for the pattern of matrix scores we observe in Table 4, we consider the relative (reported) performance of males and females. Table 6 presents, by treatment, mean reported scores separately for males and females. Under mandatory regulation, we observe that females perform worse than men: the mean score is 6.94 for males and 3.64 for females, a difference that is statistically significant $\left(\mathrm{t}_{28}=2.44, \mathrm{p}=0.02\right)$. The difference in performance under regulation might explain why women are less likely than men to opt for regulation (as we observed in Table 5).

\section{Insert Table 6 about here}


Consistent with the idea that females are using the opportunity to misreport scores as a means of "catching up" with male scores, we see that in the no-regulation condition, the difference between male and female scores is small - in fact, reversed - and statistically insignificant. Thus, when females all have the opportunity to misreport, the gender gap in scores disappears. Moreover, when we consider the treatments with voluntary regulation, we see that the difference between male and female scores varies and that it tends to be smaller and less statistically significant in the private conditions, where there is less social pressure to adopt the regulation. Thus, consistent with the idea that disadvantaged individuals disproportionately opt to forgo regulation, we observe that females tend to be disadvantaged in the task, that they tend to forgo regulation in greater proportions, and that a lack of regulation allows them to overcome their disadvantage.

\subsection{2. "License to cheat" effect}

In addition to the effect of selection on reported matrix scores, we also consider the possibility that the degree of misreporting is higher when participants opt for voluntary regulation. To do so, we attempt to identify the degree of additional misreporting when participants are unregulated voluntarily.

We first construct a rough measure of the predicted score a participant would obtain if regulated. We do this by considering all of the collected demographic variables and the extent to which they predict scores in the condition in which regulation is mandatory - i.e., when we know that scores are reported truthfully. We find one variable that reliable predicts scores: whether a participant is male or female (see Table 6). Using the gender variable, we construct a predicted score for each participant: 3.64 for female and 6.94 for males, a classification that accounts for 18 percent of the variance in actual scores. ${ }^{7}$

Next, we compare the predicted "true" scores obtained above with the actual reported scores obtained in each treatment. Table 7 presents the mean difference between participants' predicted and actual scores, by treatment and by whether or not the participant was regulated. The predicted scores represent the mean scores one would expect to observe in each case, under the assumption of no misreporting, after controlling for the gender composition of the sample producing those scores; the numbers in the table are the actual departure from this prediction. ${ }^{8}$

\section{Insert Table 7 about here}

The first row of the table corresponds to the no-regulation condition and reveals that, on average, participants reported solving 3.56 more matrices than their predicted scores. This indicates that there was

\footnotetext{
${ }^{7}$ The nature and significance of these results do not change if we use less reliable variables to generate predicted scores. For instance, including variables such as major and whether a subject's parents attended college increases the variance explained in the initial model up to $50 \%$ but does not change the conclusion of our analysis in this section. ${ }^{8}$ Since the predicted scores were obtained from the exogenous regulation treatment, the difference is by definition zero, and we exclude that treatment from the table.
} 
some misreporting relative to the case in which all participants were regulated. Across all voluntaryregulation conditions, those participants who choose to be regulated reported solving 2.61 matrices more, on average, than their predicted scores. This increase is consistent with selection on (unobserved) ability, which we discussed above.

However, the most striking aspect of Table 7 is the average reported score of participants who were unregulated: these participants reported solving 9.56 more matrices, on average, than their predicted scores. This is over 2.5 times higher than when all participants are unregulated, and the difference in means between voluntary regulation and no regulation, for those who are not regulated, is statistically significant $\left(\mathrm{t}_{147}=5.66, \mathrm{p}<0.001\right)$. The distributions also differ significantly in a non-parametric rank-sum test $(\mathrm{z}=4.88, \mathrm{p}<0.001)$. This finding is consistent with our interpretation that choosing to be unregulated, in contrast with regulation being entirely absent, give participants who opt for no regulation a "license to cheat" and leads to higher misreporting than when all participants are unregulated.

\subsection{The presence of ethical spillovers}

Finally, we can explore whether any of our treatments in the first (matrix) task, which differed in the extent to which participants were regulated, led to any differences in reported die-roll scores in the second task, when all participants were unregulated. That is, does the presence, absence, or voluntary nature of regulation in the first task create spillovers to the second task, when regulation does not exist?

\section{Insert Figure 2 about here}

Figure 2 reports the distributions of reported die rolls, in task 2, by the preceding regulation condition in task 1. Following the mandatory-regulation condition, the mean reported die roll is 3.93 , which is only slightly higher than the expected mean roll of 3.5, and the difference is not statistically significant $\left(\mathrm{t}_{29}=1.38, \mathrm{p}=0.18\right)$. Thus, when everyone in the first task is regulated, behavior is generally ethical in the second task, in the sense that there appears to be little misreporting. However, when the first task is conducted under either no regulation or under voluntary regulation, mean die rolls are higher: 4.60 and 4.69, respectively, and these both differ significantly from $3.5\left(\mathrm{t}_{29}=3.65, \mathrm{p}=0.001 ; \mathrm{t}_{215}=11.66, \mathrm{p}<\right.$ 0.001 , respectively).

Table 8 presents ordered probit regressions of the reported task 2 die-roll score on task 1 treatment and demographic variables; the omitted category is mandatory regulation, meaning that the reported coefficients measure differences with this treatment. In the first column, we find that task 2 misreporting is significantly higher following the no-regulation and voluntary-regulation conditions. The magnitude of misreporting is similar in both conditions; we fail to reject the restriction that the two coefficients in the first regression are equal $\left(\chi^{2}(1)=0.13, p=0.72\right)$. The second model estimates the differences separately for each voluntary-regulation condition. We find similar degrees of misreporting in 
all of the voluntary-regulation conditions; we fail to reject the restriction that all of the coefficients in the second model are equal $\left(\chi^{2}(4)=0.88, p=0.93\right)$. Thus, misreporting in the second (die-roll) task is present in all conditions in which participants had the opportunity to misreport in the first (matrix) task, and the degree of misreporting is equal across all such conditions.

\section{Insert Table 8 about here}

In column 3, we find that misreporting of die-roll scores among those who previously experienced voluntary regulation is driven primarily by those who opted for no regulation. Thus, the choice not to be regulated in task 1 suggests an individual type that is likely to engage in misreporting, as measured by the second (die-roll) task. This might suggest that females - who opt for no regulation and appear to misreport scores to a greater extent than males in the first task - might also engage in greater misreporting in the second task. The fourth model, however, finds that females do not report higher dieroll scores than males; in fact, they report slightly lower scores than males (4.41 vs. 4.73). This stands in contrast to our results from the first task and suggests that females only exhibit a greater propensity to misreport when they are at a disadvantage (in our case, in task 1, because females' ability is lower than that of the males, as measured in the mandatory-regulation condition). We interpret this as evidence that females are not necessarily more inclined to misreport than males; otherwise, they likely would do so in the die-roll task as well. Instead, it suggests that women (or perhaps any other group) are more likely to opt for the opportunity to engage in misreporting when they are at a competitive disadvantage in order to make up for the disadvantage. Therefore, in task 1 , when women were at a disadvantage, they chose to self-grade and engaged in more misreporting. However, in the die-roll task, in which everyone was on equal competitive footing, this greater willingness to misreport disappears.

\section{Discussion and Conclusion}

In this paper, we studied what happens when individuals can avoid or circumvent regulation and monitoring intended to curb unethical conduct. This ability effectively makes regulation voluntary. We compare our results against the null hypothesis that voluntary regulation should have similar effects as the complete absence of regulation.

Consistent with other research (e.g., Gibson, et al., forthcoming; Gneezy, 2005; Gino et al., 2009; Mazar et al., 2008), we find that participants in a condition in which regulation is entirely absent report higher scores than when all scores are verified, though they do not fully exploit their ability to lie. However, we also find that when participants must first voluntarily decide whether to have their scores regulated, a significant proportion of participants opt for regulation, yet net misreporting is higher. We find evidence that those who opt for no regulation tend to be those who are likely to perform worse at the 
competitive task and that the act of opting for no regulation induces greater misreporting - i.e., it provides individuals with a license to cheat to a greater extent.

In examining potential explanations for our pattern of findings, we highlighted an additional set of results. In the first (matrix) task, we observed a significant difference in baseline (regulated) performance among men and women; men performed better at the task. We also observed that women opted for less regulation when it was voluntary and also appeared to engage in more misreporting. Thus, an observable characteristic, gender, accounted for who did worse with no misreporting, who opted for less regulation, and who engaged in more misreporting. Yet, women did not misreport more frequently on a second task that did not involve competition based on ability. Our work is therefore related to previous research in economics that examines the link between gender and competition. For instance, Gneezy et al. (2003) found that women do not increase their effort as systematically as men in competitive settings. Similarly, Gneezy and Rustichini (2004) found that boys responded more strongly than girls to competition. ${ }^{9}$ Furthermore, related work demonstrates women are less likely to opt for competition than men are (Niederle and Vesterlund, 2007). At first impression, our work can be interpreted as evidence that, when faced with the possibility of avoiding direct competition and instead misreporting one's score, women do so more than men. Thus, one might view the gender differences we find in the first (matrix) task as evidence that women circumvent competition by engaging in cheating.

However, we find that there is no higher disposition to misreport among women in the second (die-roll) task. Therefore, our findings are subtler than simply "women cheat more on competitive tasks." Instead, we interpret our findings as evidence that, in competitive situations, disadvantaged groups will be more likely to forgo regulation to eliminate their competitive disadvantage. Thus, the greater avoidance of regulation and misreporting by women appears to be context-specific and limited to environments in which women are competitively disadvantaged. In this vein, our results share features with recent findings by Schwieren and Weichselbaumer (2010), who found that women engaged in cheating behavior more often than men, but that this was less related to a gender difference than to differences in ability.

Our results yield important policy implications. First, we demonstrate that regulation that can be avoided produces more unethical conduct than simply an absence of regulation does. This counterintuitive finding results from greater misreporting when individuals opt for the ability to misreport than when it is simply given to them. Thus, giving individuals or firms the ability to influence the degree of regulation or monitoring to which they are subject may perversely encourage those who choose lax regulations to behave more unethically than if no regulation were present. The fact that some individuals choose to open offshore bank accounts that allow them to hide earnings from tax authorities may lead them to subsequently hide earnings to a greater extent than they would if they could do so by law with all

\footnotetext{
${ }^{9}$ But, see also Dreber, von Essen, and Ranehill (2011) for contrasting results.
} 
bank accounts. Similarly, giving employees or students the discretion of whether to have their behavior monitored or verified may yield more unethical conduct. For instance, an employee who chooses a job in which their hourly effort is not monitored over one with stricter monitoring may in turn exert less effort as a consequence of this initial choice. Broadly, our results suggest the need to think carefully about the possibility that easily avoidable regulation may yield outcomes that are worse than simply having no regulation.

Our results also suggest that, in competitive situations, those who seek to avoid regulation may be those who are competitively disadvantaged in the underlying domain. Conversely, those who feel more confident in their ability to win without misreporting may opt to be regulated, perhaps out of a willingness to signal to outsiders that they do not need to cheat. Thus, voluntary regulation has the interesting property of allowing those who are disadvantaged a greater opportunity to catch up to those with greater skill. This is particularly true in contexts where there is no outside pressure to adopt regulation (as in our private treatments).

We also find some interventions that can be used to influence the willingness to abide by regulation. Making regulation choices public increases the adoption of voluntary regulation. Having early movers opt for regulation also influences those who make choices subsequently. Thus, a policymaker interested in obtaining compliance with regulation may be able to rely on social influences to achieve this result.

Finally, an important open question deals with how our results translate to other settings. For example, we use a competitive task, for reasons we describe earlier in the paper. But it is not transparent that our results would also be obtained in contexts in which individuals are not competing, as is the case, for example, under piece-rate compensation. In such contexts, the importance of relative skill is likely to be weaker, diminishing the need for the disadvantaged group to opt for less regulation and engage in more misreporting. Nevertheless, our context is similar to that in many economics and organizational settings, where success is based on relative performance and where individuals or firms can select among varying degrees of transparency. Our findings suggest that, at least in some such contexts, the possibility of voluntary regulation can yield perverse outcomes. 


\section{References}

Akerlof, G. and R. Kranton. 2010. Identity Economics, Princeton University Press.

Andreoni, J., B. Erard and J. Feinsetein. 1998. Tax Compliance. Journal of Economic Literature, 36(2): 818-860.

Asch, S. 1956. Studies of Independence and Conformity: A Minority of One Against a Unanimous Majority. Psychological Monographs, 70(9): 1-70.

Ariely, D., A. Bracha, and S. Meier (2009). Doing Good or DoingWell? Image Motivation and Monetary Incentives in Behaving Prosocially. American Economic Review, 99(1), 544-555.

Ausubel, L. 1991. The Failure of Competition in the Credit Card Market, The American Economic Review, 81(1): 50-81.

Ayal, S., and Gino, F. 2011. Honest rationales for dishonest behavior. In M. Mikulincer \& P. R. Shaver (Eds.), The Social Psychology of Morality: Exploring the Causes of Good and Evil. Washington, DC: American Psychological Association.

Bateson, M., D. Nettle and G. Roberts. 2006. Cues of Being Watched Enhance Cooperation In A RealWorld Setting. Biology Letters, 2: 412-114.

Bicchieri, C. and E. Xiao. 2009. Do the right thing: but only if others do so. Journal of Behavioral Decision Making. 22 191-208.

Brass, D., K. Butterfield and B. Skaggs. 1998. Relationships and Unethical Behavior: A social Network Perspective, The Academy of Management Review, 23(1): 14-32.

Burnham, T. and B. Hare. 2007. Does Involuntary Neural Activation Increase Public Goods Contributions In Human Adults? Human Nature 18: 88 -108.

Burks, S. and E. Krupka. 2012. A Multi-method approach to identifying norms and normative expectations within a corporate hierarchy: Evidence from the financial services industry, Management Science.

Carpenter, J., P. Matthews, J. Schirm. 2010. Tournaments and Office Politics: Evidence from a Real Effort Experiment, The American Economic Review, 100(1): 504-517.

Charness, G., L. Rigotti and A, Rustichini. 2007. Individual Behavior and Group Membership, The American Economic Review, 97(4):1340-1352.

Croson, R.T.A. 2005. Deception in Economic Experiments, In Deception in Markets:An Economic Analysis. ed. Caroline Gerschlager, 113-130. New York: Palgrave Macmillan.

Dana, J., Loewenstein, G., and Weber, R. A. 2011. Ethical immunity: How people violate their own moral standards without feeling they are doing so. In Ann E. Tenbrunsel and David De Cremer (Eds.), Behavioral Ethics: Ideas on an Emerging Field, Taylor \& Francis. 
Deutsch, M. and Gerard, H. 1955. A Study of Normative and Informational Social Influences upon Individual Judgment, The Journal of Abnormal and Social Psychology, 51(3): 629-636.

Diekmann, K.A., Tenbrunsel, A.E., and Galinsky, A.D. 2003. From self-prediction to self-defeat: Behavioral forecasting, self-fulfilling prophecies, and the effect of competitive expectations. Journal of Personality and Social Psychology, 85: 672-683.

Dohmen, T. and Armin Falk. 2011. Performance pay and multidimensional sorting: Productivity, preferences, and gender. American Economic Review, 101(2), 556-90.

Ellman, M., and P. Pezanis-Christou. 2010. Organizational structure, communication, and group ethics. American Economic Review, 100(5): 2478-91

Erat, S. and U. Gneezy. forthcoming. White Lies. Management Science. Pp. 1-11.

Freedman, J., and S. Fraser, S. 1966. Compliance Without Pressure: The foot-in-the-door Technique, Journal of Personality and Social Psychology, 4:196-202.

Fischbacher, U., and F. Heusi. 2008. Lies in disguise. An experimental study on cheating. TWI Research Paper Series 40.

Fisman, R. and R. Gatti. 2002. Decentralization and Corruption: Evidence Across Countries, Journal of Public Economics, 83:325-345.

Gibson R., Tanner C., Wagner A. forthcoming. Preferences for truthfulness: Heterogeneity among and within individuals. American Economic Review.

Gino, F., and Ariely, D. 2012. The dark side of creativity: original thinkers can be more dishonest. Journal of Personality and Social Psychology, 102(3), 445-459.

Gino, F., S. Ayal and D. Ariely. 2009. Contagion and Differentiation in Unethical Behavior: The Effect of One Bad Apple on the Barrel. Psychological Science, 20(3): 393-398.

Gino, F., and Galinsky, A. 2012. Vicarious dishonesty: When psychological closeness creates distance from one's own moral compass. Organizational Behavior and Human Decision Processes, 119(1): 15-26.

Gino, F., J. Gu and C. Zhong 2009. Contagion or restitution? When bad apples can motivate ethical behavior. Journal of Experimental Social Psychology, 45(6), 1299-1302.

Gneezy, U. 2005. Deception: The Role of Consequences. American Economic Review. 95(1) 384-394.

Gneezy, U., and A. Rustichini. 2004. Gender and competition at a young age. American Economic Review, 94(2): 377-381.

Gneezy, U., M Niederle, and A. Rustichini. 2003. Performance in competitive environments: Gender differences. Quarterly Journal of Economics, 118(3), 1049-1074.

Goldstein, N. J., R. Cialdini and V. Griskevicius. 2011. A room with a viewpoint: Using social norms to motivate environmental conservation in hotels. Journal of Consumer Research. 
Hamman, J., Weber, R. and Loewenstein, G. 2010. Self-interest through delegation: An additional rationale for the principal-agent relationship. American Economic Review, 100(4): 1826-1846.

Hanna, R. 2010. US Environmental Regulation and FDI: Evidence from a Panel of US-Based Multinational Firms, American Economic Journal: Applied Economics, 2:158-189.

Haley, K. and D. Fessler. 2005. Nobody's watching? Subtle Cues Affect Generosity In An Anonymous Economic Game. Evolutionary Human Behavior 26: 245-256.

Hurkens, S. and N. Kartik. 2009. Would I lie to you? On social preferences and lying aversion. Experimental Economics. 12: 180-192.

Jones, G. and M. Kavanagh. 1996. An Experimental Examination of the Effects of Individual and Situational Factors on Unethical Behavioral Intentions in the Workplace. Journal of Business Ethics, 15:511-523.

Kallgren, C., R. Reno, and R. Cialdini. 2000. A Focus Theory Of Normative Conduct: When Norms Do And Do Not Affect Behavior. Personality and Social Psychology Bulletin, 26(8): 1002-1012.

Keizer, K.; S. Lindenberg and L. Steg. 2008. The Spreading of Disorder. Science, 322(5908): 1681-1685.

Krupka, E., and Weber, R. 2009. The focusing and informational effects of norms on pro-social behavior. Journal of Economic Psychology. 30(3) 307-320.

Levinson, A. and M.Taylor. 2008. Unmasking the Pollution Haven Effect. International Economic Review 49(1):223-254.

Mazar, N., Amir, O., and Ariely, D. 2008. The dishonesty of honest people: A theory of self-concept maintenance. Journal of Marketing Research, 45: 633-644.

Mead, N., R. Baumeister, F. Gino, M. Schweitzer and D. Ariely. 2009. Too tired to tell the truth: Selfcontrol resource depletion and dishonesty. Journal of Experimental Social Psychology, 45(3), 594-597.

Nagin, D. S., J. B. Rebitzer, S. Sanders and L. J. Taylor. 2002. Monitoring, motivation, and management: The determinants of opportunistic behavior in a field experiment. American Economic Review, 92(4), 850-873.

Niederle, M., and L. Vesterlund. 2007. Do women shy away from competition? Do men compete too much? Quarterly Journal of Economics, 122(3): 1067-1101.

Olken, Benjamin. 2007. Monitoring Corruption: Evidence from a Field Experiment in Indonesia. Journal of Political Economy: 200-249

Pierce, L. and J. Snyder. 2008. Ethical spillovers in firms: evidence from vehicle emissions testing, Management Science, 54(11): 1891-1903.

Rigdon, M., K. Ishii, M. Watabe, and S. Kitayama. 2009. Minimal social cues in the dictator game. Journal of Economic Psychology, 30, 358 - 367. 
Schminke, M., M. Ambrose and D. Neubaum. 2005. The Effect of Leader Moral Development on Ethical Climate and Employee Attitudes, Organizational Behavior and Human Decision Processes, 97:135-151.

Schultz, P. W., J. Nolan, R. Cialdini, N. Goldstein and V. Griskevicius. 2007. The constructive, destructive, and reconstructive power of social norms. Psychological Science, 18, 429-434.

Schwieren, C., and Weichselbaumer, D. 2010. Does competition enhance performance or cheating? A laboratory experiment. Journal of Economic Psychology, 31(3), 241-253

Shalvi, S., Dana, J., Handgraaf, M. J. J., and De Dreu, C. K. W. 2011. Justified ethicality: Observing desired counterfactuals modifies ethical perceptions and behavior. Organizational Behavior and Human Decision Processes, 115: 181-190.

Sherman, S. 1980. On The Self-Erasing Nature Of Errors of Prediction, Journal of Personality and Social Psychology, 39(2): 211-221.

Sutter, M. 2009. Deception Through Telling the Truth! Experimental Evidence from Individuals and Teams. Economic Journal, 119(534):47-60.

Tenbrunsel, A., K. Diekmann, K. Wade-Benzoni and M. Bazerman 2011. The Ethical Mirage: A Temporal Explanation as to Why We Aren't as Ethical as We Think We Are. Research in Organizational Behavior.

Trevino, L., G. Weaver and M. Brown. 2008. It's Lovely at the Top: Hierarchical Levels, Identities, and Perceptions of Organizational Ethics, Business Ethics Quarterly, 18(2): 233-252.

Trope, Y. and N. Liberman. 2010. Construal-Level Theory of Psychological Distance, Psychological Review, 117(2): 440-463.

Zey-Ferrell, M., K. Weaver and O. Ferrell. 1979. Predicting Unethical Behavior Among Marketing Practitioners. Human Relations, 32:557-561.

Zey-Ferrell, M. and O. Ferrell. 1982. Role-Set Configuration and Opportunity as Predictors of Unethical Behavior in Organizations. Human Relations, 35(7): 587-604.

Woodzicka, J. A. and LaFrance, M. 2001. Real versus imagined gender harassment. Journal of Social Issues, 57: 15-30. 


\section{Tables}

Table 1. Experimental design overview

\begin{tabular}{|c|c|c|c|c|}
\hline & \multicolumn{2}{|c|}{ Voluntary Regulation } & \multicolumn{2}{|c|}{ Mandatory } \\
\hline & $\begin{array}{l}\text { Sequential } \\
\text { Choice }\end{array}$ & $\begin{array}{l}\text { Simultaneous } \\
\text { Choice }\end{array}$ & Regulation & No Regulation \\
\hline Public Choice & $\begin{array}{c}N=54 \\
(9 \text { sessions })\end{array}$ & $\begin{array}{c}\mathrm{N}=54 \\
(9 \text { sessions })\end{array}$ & $\begin{array}{c}\mathrm{N}=30 \\
(5 \text { sessions })\end{array}$ & $\begin{array}{c}\mathrm{N}=30 \\
(5 \text { sessions })\end{array}$ \\
\hline Private Choice & $\begin{array}{c}\mathrm{N}=54 \\
(9 \text { sessions })\end{array}$ & $\begin{array}{c}\mathrm{N}=54 \\
(9 \text { sessions })\end{array}$ & & \\
\hline
\end{tabular}

Table 2. Outcomes from the matrix task by condition

\begin{tabular}{|llc|}
\hline Treatment & $\begin{array}{c}\text { Mean score } \\
\text { (std. dev.) }\end{array}$ & $\begin{array}{c}\text { Frequency of } \\
\text { regulation }\end{array}$ \\
\hline No Regulation & $9.07(3.78)$ & 0 \\
\hline Mandatory Regulation & $5.40(4.00)$ & 1 \\
\hline Voluntary Regulation (Pooled - all conditions) & $12.20(5.67)$ & 0.421 \\
\hline Voluntary Regulation (Private-Simultaneous) & $13.48(5.55)$ & 0.296 \\
\hline Voluntary Regulation (Private-Sequential) & $13.67(5.65)$ & 0.333 \\
\hline Voluntary Regulation (Public-Simultaneous) & $10.26(5.51)$ & 0.537 \\
\hline Voluntary Regulation (Public-Sequential) & $11.39(5.37)$ & 0.519 \\
\hline
\end{tabular}

Note: Standard deviations are in parentheses. 
Table 3. Endogenous regulation choices by position (ID) in sequential-public condition

\begin{tabular}{|c|ccccccccc|}
\hline & \multicolumn{10}{|c|}{ Session } \\
\hline \hline ID & S2 & S9 & S10 & S31 & S7 & S19 & S22 & S26 & S43 \\
\hline 1 & 1 & 1 & 1 & 1 & 0 & 0 & 0 & 0 & 0 \\
\hline 2 & 1 & 1 & 1 & 1 & 0 & 0 & 0 & 0 & 0 \\
\hline 3 & 1 & 1 & 1 & 1 & 0 & 0 & 1 & 1 & 0 \\
\hline 4 & 1 & 1 & 1 & 1 & 0 & 0 & 0 & 1 & 0 \\
\hline 5 & 0 & 1 & 1 & 0 & 0 & 1 & 1 & 1 & 0 \\
\hline \hline $\begin{array}{c}\text { Frequency of } \\
\text { regulation }\end{array}$ & 0.67 & 1.00 & 1.00 & 0.67 & 0.17 & 0.17 & 0.33 & 0.67 & 0.00 \\
\hline $\begin{array}{c}\text { Average reported } \\
\text { score }\end{array}$ & 10.2 & 8.0 & 9.5 & 11.0 & 14.3 & 14.8 & 8.5 & 9.8 & 16.3 \\
\hline $\begin{array}{c}\text { Average score } \\
\text { (excluding ID\#1) }\end{array}$ & 11.0 & 8.6 & 10.2 & 11.8 & 13.2 & 13.8 & 8.6 & 8.2 & 16.2 \\
\hline
\end{tabular}

Note: Decisions to be regulated are marked 1 and decisions to be unregulated are marked 0 . Columns in gray are those where the first subject $(\mathrm{id}=1)$ chose to be regulated.

Table 4. Mean reported matrix score broken down by regulation condition

\begin{tabular}{|llc|}
\hline \multirow{2}{*}{ Treatment } & \multicolumn{2}{c|}{ Mean reported Score } \\
\cline { 2 - 3 } No Regulation & $\begin{array}{c}\text { Unregulated } \\
\text { Participants }\end{array}$ & $\begin{array}{c}\text { Regulated } \\
\text { Participants }\end{array}$ \\
\hline Mandatory Regulation & $9.07(3.78)$ & \\
\hline Voluntary Regulation (Pooled - all conditions) & & $5.40(4.00)$ \\
\hline Voluntary Regulation (Private-Simultaneous) & $14.94(4.98)$ & $8.43(4.20)$ \\
\hline Voluntary Regulation (Private-Sequential) & $16.00(4.13)$ & $7.50(3.56)$ \\
\hline Voluntary Regulation (Public-Simultaneous) & $16.28(4.03)$ & $8.44(4.76)$ \\
\hline Voluntary Regulation (Public-Sequential) & $11.92(5.95)$ & $8.83(4.75)$ \\
\hline
\end{tabular}

Note: Standard deviations are in parentheses. 
Table 5. Marginal effects from probit regression of decision to be regulated

\begin{tabular}{|c|c|c|}
\hline Variables & 1. & 2. \\
\hline Female & $\begin{array}{c}-0.172^{* *} \\
(0.067)\end{array}$ & $\begin{array}{c}-0.192^{* * *} \\
(0.064)\end{array}$ \\
\hline Age & $\begin{array}{c}0.011 \\
(0.009)\end{array}$ & $\begin{array}{c}0.010 \\
(0.009)\end{array}$ \\
\hline Parent Graduated College & $\begin{array}{c}0.076 \\
(0.066)\end{array}$ & $\begin{array}{c}0.075 \\
(0.069)\end{array}$ \\
\hline Religious & $\begin{array}{l}-0.098 \\
(0.111)\end{array}$ & $\begin{array}{l}-0.067 \\
(0.138)\end{array}$ \\
\hline Public Treatment & $\begin{array}{l}0.242^{* * *} \\
(0.079)\end{array}$ & $\begin{array}{c}0.249^{* * *} \\
(0.076)\end{array}$ \\
\hline Major (Arts \& Humanities) & & $\begin{array}{c}0.125 \\
(0.180)\end{array}$ \\
\hline Major (Business Administration) & & $\begin{array}{c}0.001 \\
(0.148)\end{array}$ \\
\hline Major (Economics) & & $\begin{array}{c}0.015 \\
(0.206)\end{array}$ \\
\hline Major (Engineering) & & $\begin{array}{l}-0.026 \\
(0.116)\end{array}$ \\
\hline Major (Sciences) & & $\begin{array}{l}-0.048 \\
(0.113)\end{array}$ \\
\hline Major (Social Sciences) & & $\begin{array}{c}0.039 \\
(0.164)\end{array}$ \\
\hline $\begin{array}{l}\text { Observations } \\
\text { Pseudo } \mathrm{R}^{2}\end{array}$ & $\begin{array}{c}212 \\
0.069\end{array}$ & $\begin{array}{c}211 \\
0.072\end{array}$ \\
\hline
\end{tabular}

Note: ${ }^{*} \mathrm{p}<0.10,{ }^{* *} \mathrm{p}<0.05,{ }^{* * *} \mathrm{p}<0.01$ and standard errors are clustered by session and in the parentheses. 
Table 6. Mean matrix score by gender and treatment

\begin{tabular}{|lcccc|}
\hline Treatment & $\begin{array}{c}\text { Mean } \\
\text { score } \\
\text { (males) }\end{array}$ & $\begin{array}{c}\text { Mean } \\
\text { score } \\
\text { (females) }\end{array}$ & $\begin{array}{c}\text { Difference } \\
\text { (male }- \text { female) }\end{array}$ \\
\hline No Regulation & $\begin{array}{c}8.57 \\
(3.29)\end{array}$ & $\begin{array}{c}9.90 \\
(4.70)\end{array}$ & -1.33 & $\begin{array}{c}\mathrm{t}_{22}=0.82 \\
\mathrm{p}=0.42\end{array}$ \\
\hline Mandatory Regulation & $\begin{array}{c}6.94 \\
(4.20)\end{array}$ & $\begin{array}{c}3.64 \\
(3.00)\end{array}$ & 3.30 & $\begin{array}{c}\mathrm{t}_{28}=2.44 \\
\mathrm{p}=0.02\end{array}$ \\
\hline Voluntary Regulation (Pooled - Private treatments) & $\begin{array}{c}13.90 \\
(5.41)\end{array}$ & $\begin{array}{c}13.05 \\
(5.87)\end{array}$ & 0.85 & $\begin{array}{c}\mathrm{t}_{106}=0.76 \\
\mathrm{p}=0.45\end{array}$ \\
\hline Voluntary Regulation (Pooled - Public treatments) & $\begin{array}{c}12.19 \\
(5.45)\end{array}$ & $\begin{array}{c}9.18 \\
(5.02)\end{array}$ & 3.00 & $\begin{array}{c}\mathrm{t}_{106}=2.95 \\
\mathrm{p}=0.004\end{array}$ \\
\hline Voluntary Regulation (Private-Simultaneous) & $\begin{array}{c}13.30 \\
(5.14)\end{array}$ & $\begin{array}{c}13.88 \\
(6.51)\end{array}$ & -0.58 & $\begin{array}{c}\mathrm{t}_{52}=0.36 \\
\mathrm{t}=0.72\end{array}$ \\
\hline Voluntary Regulation (Private-Sequential) & $\begin{array}{c}14.63 \\
(5.71)\end{array}$ & $\begin{array}{c}12.46 \\
(5.44)\end{array}$ & 2.17 & $\begin{array}{c}\mathrm{t}_{52}=1.42 \\
\mathrm{p}=0.16\end{array}$ \\
\hline Voluntary Regulation (Public-Simultaneous) & $\begin{array}{c}11.76 \\
(5.96)\end{array}$ & $\begin{array}{c}7.90 \\
(3.77)\end{array}$ & 3.86 & $\begin{array}{c}\mathrm{t}_{52}=2.64 \\
\mathrm{p}=0.01\end{array}$ \\
\hline Voluntary Regulation (Public-Sequential) & $\begin{array}{c}12.73 \\
(4.79)\end{array}$ & $\begin{array}{c}10.14 \\
(5.65)\end{array}$ & 2.59 & $\begin{array}{c}\mathrm{t}_{52}=1.81 \\
\mathrm{p}=0.08\end{array}$ \\
\hline
\end{tabular}

Note: Standard deviations are in parentheses. 
Table 7. Mean difference between reported and predicted matrix scores in competitive task by condition

\begin{tabular}{|lcc|}
\hline Treatment & $\begin{array}{c}\text { Unregulated } \\
\text { participants }\end{array}$ & $\begin{array}{c}\text { Regulated } \\
\text { participants }\end{array}$ \\
\hline No Regulation & $3.56(4.50)$ & \\
\hline Voluntary Regulation (Pooled - all conditions) & $9.56(4.81)$ & $2.61(3.84)$ \\
\hline Voluntary Regulation (Private-Simultaneous) & $10.19(4.58)$ & $1.39(3.23)$ \\
\hline Voluntary Regulation (Private-Sequential) & $10.99(3.71)$ & $2.61(4.33)$ \\
\hline Voluntary Regulation (Public-Simultaneous) & $6.56(5.32)$ & $2.91(4.49)$ \\
\hline Voluntary Regulation (Public-Sequential) & $9.55(4.93)$ & $3.01(3.09)$ \\
\hline
\end{tabular}

Note: Standard deviations are in parentheses.

Table 8. Ordered probit regressions of reported score in die-roll task

\begin{tabular}{|l|c|c|c|c|}
\hline \multicolumn{1}{|c|}{ Variables } & $\mathbf{1 .}$ & $\mathbf{2 .}$ & $\mathbf{3 .}$ & $\mathbf{4 .}$ \\
\hline No Regulation in Task 1 & $0.47^{*}$ & $0.47^{*}$ & $0.47^{*}$ & 0.45 \\
& $(0.24)$ & $(0.24)$ & $(0.24)$ & $(0.27)$ \\
Voluntary Regulation in Task 1 & $0.53^{* * *}$ & & 0.28 & 0.24 \\
(all conditions) & $(0.19)$ & & $(0.20)$ & $(0.19)$ \\
Voluntary Regulation in Task 1 & & & $0.48^{* * *}$ & $0.52^{* * *}$ \\
(chose no regulation) & & & $(0.15)$ & $(0.14)$ \\
Voluntary Regulation in Task 1 & & $0.51^{* *}$ & & \\
(Private-Simultaneous) & & $(0.26)$ & & \\
Voluntary Regulation in Task 1 & & $0.61^{* * *}$ & & \\
(Private-Sequential) & & $(0.21)$ & & \\
Voluntary Regulation in Task 1 & & $0.45^{*}$ & & \\
(Public-Simultaneous) & & $(0.25)$ & & \\
Voluntary Regulation in Task 1 & & $0.56^{* * *}$ & & \\
(Public-Sequential) & & $(0.22)$ & & \\
Female & & & & \\
Observations & & & & \\
\hline
\end{tabular}

Note: ${ }^{*} \mathrm{p}<0.10,{ }^{* *} \mathrm{p}<0.05,{ }^{* * *} \mathrm{p}<0.01$. The standard errors (clustered by session) are reported in the parentheses. 
Figures

Figure 1. Reported matrix score for those choosing to be un/regulated by private and public conditions

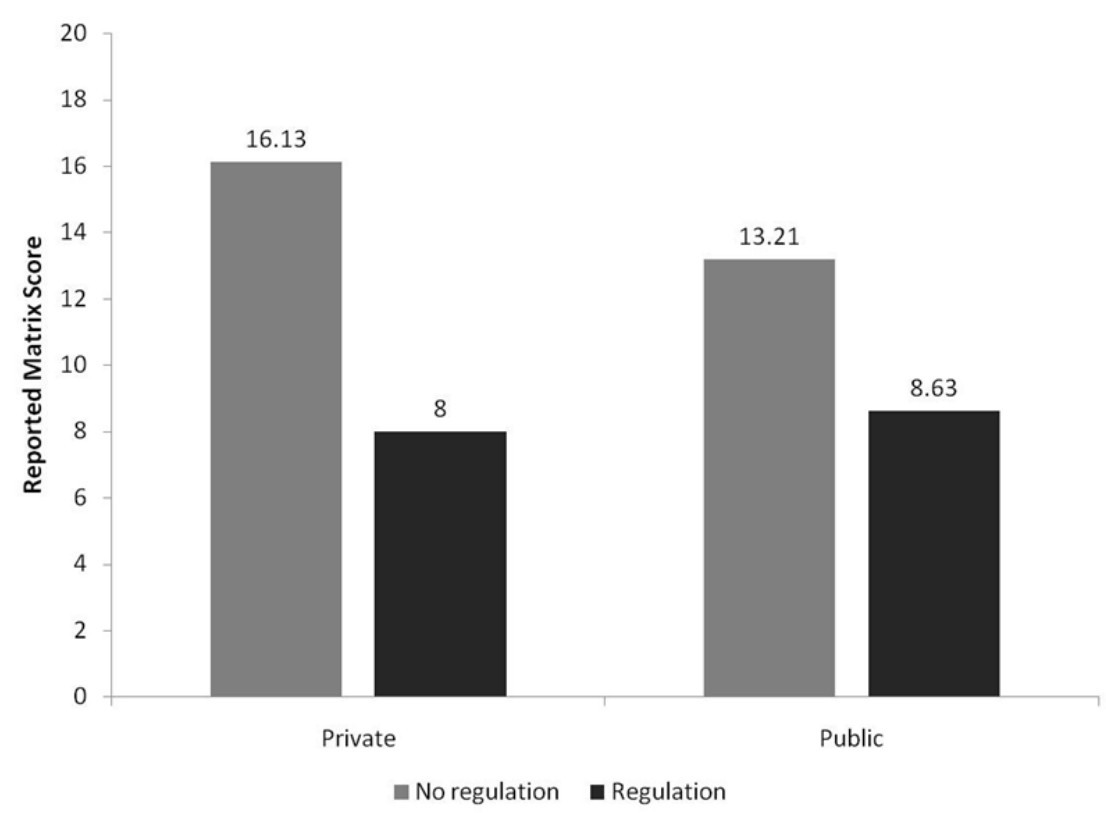

Figure 2. Reported die-roll score (Task 2) by regulation condition (in Task 1)

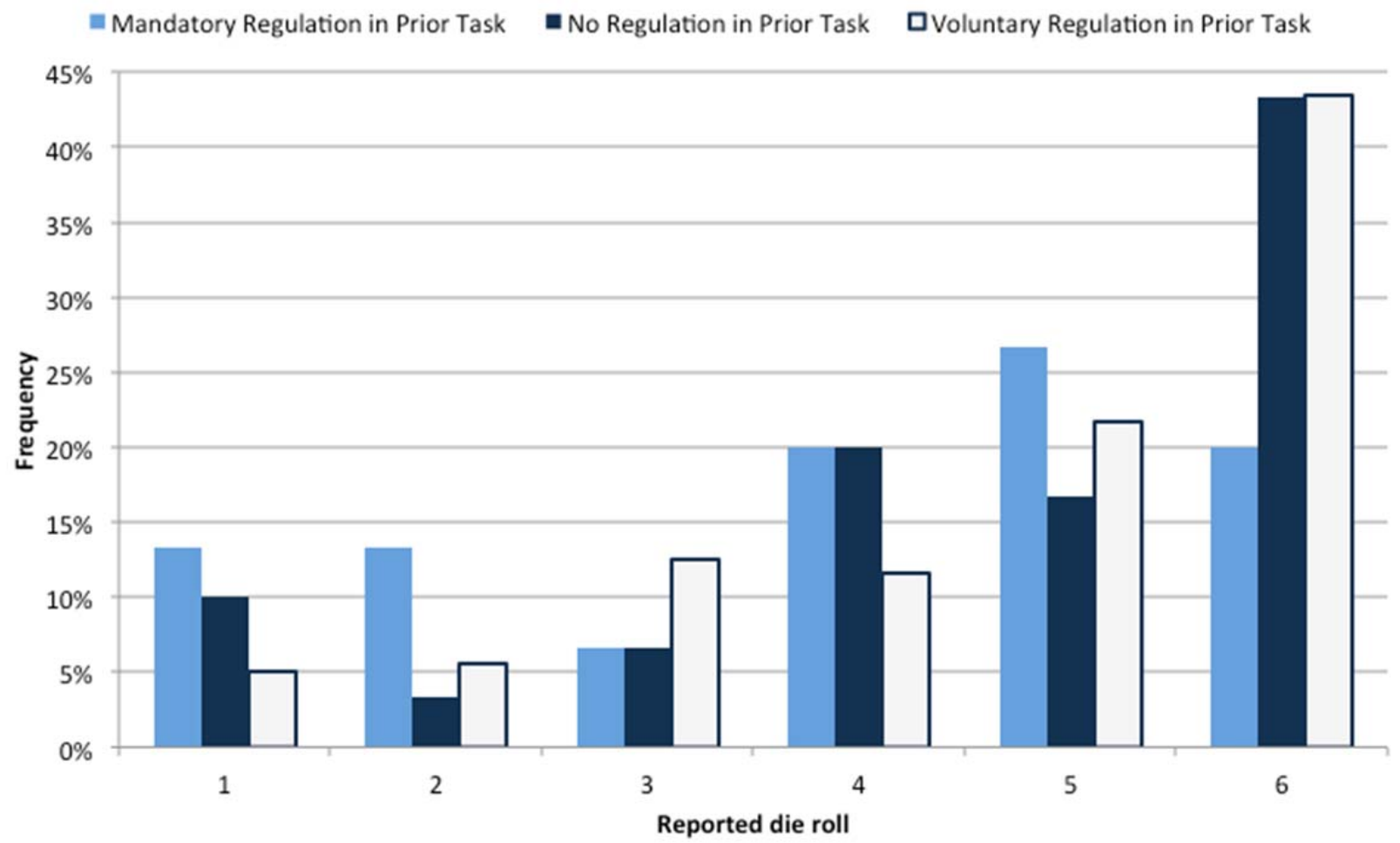

